\title{
WUJUD BAHASA ARAB DALAM MEMPERKAYA KEBUDAYAAN INDONESIA
}

\author{
Novita Rahmi \\ Institut Agama Islam Negeri (IAIN) Metro \\ Jl. Ki Hajar Dewantara 15A Iring Mulyo Kota Metro \\ Novitarahmi88@gmail.com
}

\begin{abstract}
Arabic language influence Indonesian culture along with the arrival of Arab traders to Indonesia in the 7th century Masehi, the first time they entered Indonesia through India (Gujarat) to trade, then continues as a propagator of Islam. Although Indonesia experienced an acculturation process with Hindu-Buddhist, Dutch, Japanese and other cultures, Arabic also made a huge contribution to the growth of Indonesian as a national language. Until now the form of Arabic can still be seen in various aspects of culture in Indonesia. In terms of language, there are many words that come from the Arabic words Likewise with art, Arabic is written with beautiful writing / calligraphy until now is used to decorate the mosque building and become one of the branches of MTQ. Customs in Indonesia are also heavily influenced by Arabic, sekaten ceremonies, ruwahan, etc. are evidence of Arabic acculturation in Indonesia.
\end{abstract}

Keywords: Arabic, Culture

\begin{abstract}
Abstrak
Bahasa Arab mewarnai kebudayaan Indonesia seiring dengan datangnya pedagang Arab ke Indonesia pada abad ke-7 masehi, pada mulanya mereka masuk ke Indonesia melalui India (Gujarat) untuk berdagang, kemudian berlanjut sebagai penyebar agama Islam. Walaupun Indonesia mengalami proses akulturasi dengan budaya Hindu-Budha, Belanda, Jepang, dan lainnya namun bahasa Arab juga memberikan sumbangan yang sangat besar dalam pertumbuhan bahasa Indonesia sebagai bahasa nasional. Hingga sekarang wujud bahasa Arab masih dapat terlihat di berbagai aspek kebudayaan di Indonesia. Dari segi bahasa, banyak ditemui kata-kata yang berasal dari kata bahasa arab Begitu juga dengan seni, bahasa Arab yang ditulis dengan tulisan indah/kaligrafi sampai sekarang digunakan untuk menghiasi bangunan masjid dan menjadi salah satu cabang MTQ. Adat istiadat di Indonesia juga banyak dipengaruhi oleh bahasa Arab, upacara sekaten, ruwahan, khitanan/sunatan, dll menjadi bukti adanya akulturasi bahasa Arab di Indonesia..
\end{abstract}

Kata Kunci: Bahasa Arab, Kebudayaan

\section{Pendahuluan}

Manusia dan kebudayaan adalah satu kesatuan yang tidak dapat dipisahkan. Ada manusia maka ada kebudayaan, tidak ada kebudayaan tanpa adanya manusia.
Kebudayaan merupakan segala sesuatu yang dihasilkan oleh akal fikiran manusia. Manusia sebagai makhluk Allah SWT diberi keistimewaan berupa akal fikiran dan kecerdasan otak. Hal inilah yang mem- 
bedakan manusia dengan makhluk lainnya seperti hewan atau binatang. Pada umumnya hewan berbuat dan bekerja sesuai dengan nalurinya, jika ia merasa lapar maka ia akan mencari makanan. Namun ketika makanan yang didapatkan tersebut berlebih atau ada sisa, hewan tidak akan berfikir bagaimana cara menyimpannya untuk hari esok. Berbeda dengan manusia yang lebih berfikir panjang, dengan akalnya manusia dapat memikirkan bagaimana cara mempertahankan hidupnya, seperti menciptakan alat untuk menyimpan dan mengawetkan makanan.

Lebih dari itu, manusia memiliki kecakapan menyerahkan pekerjaan yang seharusnya dilakukan dengan kekuatan tangannya sendiri kepada yang lain, baik berupa alat maupun dengan bantuan hewan, dari yang paling sederhana sampai kepada alat canggih sesuai dengan kemajuan ilmu dan teknologi. Kecakapan menyerahkan pekerjaan ini menjadi faktor penting yang menyebabkan kemajuan dan pengembangan hasil-hasil daya cipta manusia. Semua hasil daya cipta manusia inilah yang dinamakan dengan kebudayaan.

Sebagai makhluk sosial, perkembangan manusia menginspirasi adanya perkembangan budaya, baik secara vertikal/turun temurun ataupun horizontal/ lingkungan sekitar. Dengan teknologi, manusia mampu berinteraksi tanpa batas waktu dan tempat. Secara tidak langsung kebudayaan yang dimiliki oleh suatu negara tidak mutlak hanya menjadi miliknya, negara lain pun dapat menikmati dan merasakan budaya tersebut baik dengan interaksi langsung ataupun interaksi tidak langsung. Manusia berinteraksi dengan menggunakan bahasa sebagai alat komunikasi. Jika kita telusuri dari sejarah masa lampau, orang-orang Arab yang datang ke Indonesia juga melakukan akulturasi dari suatu kebudayaan, terutama bahasa yang mereka gunakan, yaitu bahasa Arab. Terlebih lagi bahasa Arab ini adalah bahasa resmi agama Islam. Indonesia sebagai negara yang memiliki penduduk mayoritas beragama Islam tentu akan mempelajari bahasa Arab untuk memahami ajaran-ajaran yang dimiliki oleh agama Islam dan menggunakannya dalam keseharian. Bahasa Arab digunakan di dalam sholat, membaca AlQur'an, berdoa, sebagai mata pelajaran di sekolah, sampai kepada penulisan huruf Arab/kaligrafi yang memperindah bangunan-bangunan dan masjid-masjid di Indonesia. Dari waktu ke waktu, bahasa Arab semakin melekat dengan aktivitas sehari-hari. Terjadinya pengulangan hingga menjadi kebiasaan adalah awal munculnya dari suatu kebudayaan. Bagaimana bahasa Arab mewarnai kebudayaan Indonesia? Berikut ini penulis akan memaparkan wujud bahasa Arab dalam memperkaya kebudayaan Indonesia, yang mencakup: bahasa, seni, dan adat istiadat yang ada di Indonesia. 


\section{Pembahasan}

\section{Kebudayaan dan Awal Masuknya Bahasa Arab di Indonesia}

Menurut Koentjaraningrat, kebudayaan berasal dari kata "budhayah" yang merupakan bentuk jamak dari "budhi" yang berarti budi atau akal. Berdasarkan asal kata ini kebudayaan diartikan sebagai hal yang bersangkutan dengan akal. ${ }^{1}$

Berdasarkan pemakaian kata kebudayaan dari berbagai masyarakat ditunjukkan bahwa pada dasarnya kebudayaan berbicara mengenai sifat-sifat dasar manusiawi, yaitu bagaimana manusia mengembangkan bakat akal budinya dalam menghadapi kehidupannya.

Jika hewan dapat membuat rumahnya sendiri dari waktu ke waktu bentuknya tidak akan berubah, berbeda dengan hasil ciptaan manusia yang terus mengalami perubahan dan perkembangan. Manusia mempunyai hasrat ingin tahu yang menimbulkan keinginan untuk belajar dan terus belajar. Dari hasrat inilah memungkinkan kebudayaan manusia itu terus berlangsung, berubah dan berkembang secara turun temurun. Hasrat akan keindahan akan melahirkan "kesenian", hasrat yang menunjukkkan ketidakmampuan dan kelemahan manusia maka akan menimbulkan "agama dan kepercayaan", hasrat akan perlunya aturan, tata tertib dan kesopanan melahirkan "adat

1 Koentjaraningrat, Kebudayaan Mentalitas Pembangunan, (Jakarta: Gramedia, 1990), h. 5 istiadat", dan banyak contoh lainnya.

Kebudayaan tidak hanya berkembang secara vertikal atau turun temurun sesuai dengan garis keturunan, tetapi juga berkembangan secara horizontal atau mendatar kepada orang lain di sekitarnya. Manusia disebut juga makhluk sosial yang tidak bisa hidup sendiri. Pembentukan kelompok merupakan kebutuhan yang mutlak. Mulai dari kelompok terkecil yang disebut dengan keluarga, sampai dengan kelompok yang lebih besar yang disebut dengan masyarakat. Dengan demikian pergaulan satu anggota akan diteruskan dan dikomunikasikan kepada anggota lainnya, secara tidak langsung akan bergabung pula kepandaian, hasil fikiran, pandangan hidup, bahasa, adat istiadat yang semuanya itu disebut juga dengan kebudayaan.

Menjalin hubungan dengan bangsa lain akan melahirkan pertukaran hasil pemikiran, seni dan sebagainya. Sehingga di antara kedua bangsa itu saling memberi dan menerima informasi. Proses untuk meneruskan, mengkomunikasikan dan mengembangkan budaya ini terjadi karena adanya proses "menyimak" dan "berbicara" yang merupakan unsur penting dalam bahasa. Di dalam bahasa terdapat proses peniruan yang merupakan salah satu fitrah manusia, karena tanpa proses peniruan manusia tidak dapat berbicara dan belajar. $^{2}$

\footnotetext{
${ }^{2}$ Akhmad Muzakki, Pengantar Teori Sastra Arab, (Malang: UIN Maliki Press, 2011), h. 104-105
} 
Kebudayaan suatu kelompok, golongan atau milik suatu bangsa dalam kehidupan sehari-hari kenyataannya tidak mutlak menjadi hak milik bangsa itu sendiri, pada umumnya sering terjadi pencampuran kebudayaan suatu bangsa dengan kebudayaan bangsa lain. Proses pencampuran dan penyebaran kebudayaan dari suatu bangsa ke bangsa yang lain dapat melalui berbagai cara, seperti diffusi dan akulturasi. Cara diffusi yaitu proses pencampuran unsur-unsur kebudayaan (dalam hal ini termasuk bahasa) dari suatu bangsa ke bangsa lain melaui media perantara tanpa kedua bangsa tersebut bertemu atau hidup bersama untuk mengenal kebudayaan masing-masing, misalnya melaui bukubuku, surat kabar, majalah, film, televisi, dan lain-lain. Sedangkan cara akulturasi adalah sebaliknya, bangsa-bangsa pendukung kebudayaan tersebut bertemu dan hidup bersama, saling mengenal dan akhirnya saling memberi dan menerima kebudayaan masing-masing yang disesuaikan dengan kehidupannya sendiri, dan dari proses pencampuran kebudayaan ini akan lahirlah kebudayaan yang baru. ${ }^{3}$

Salah satu contoh pencampuran kebudayaan secara akulturasi adalah kebudayaan Indonesia yang dipengaruhi oleh kebudayaan Arab datangnya orang-

\footnotetext{
${ }^{3}$ Bahrum Rangkuti dan Kafrawi, Pedoman Pengajaran Bahasa Arab, (Jakarta: Proyek Pengembangan Sistim Pendidikan Agama Departemen Agama RI, 1974), h. 95
}

orang Arab ke Indonesia pada abad ke-7 masehi, pada mulanya sebagai pedagang yang masuk melalui India (Gujarat), kemudian berlanjut sebagai penyebar agama Islam, terjadi pencampuran budaya secara akulturasi karena adanya pengaruh pergaulan berdasarkan kepentingan dalam berdagang, ditambah lagi pengaruh agama Islam yang relatif cepat dapat diterima oleh bangsa Indonesia yang sejak awal sudah memiliki dasar-dasar religius. Sejak itulah bahasa sebagai salah satu unsur kebudayaan dengan sendirinya mengalami pencampuran dan pemindahan secara akulturasi, artinya bahasa Arab yang dibawa oleh orang Arab mengalami proses akulturasi dengan bahasa Indonesia. Walaupun Indonesia juga mengalami proses akulturasi dengan budaya Hindu-Budha, Belanda, Jepang, dan lainnya namun bahasa Arab juga telah memberikan sumbangan yang sangat besar dalam pertumbuhan bahasa Indonesia sebagai bahasa nasional.

Jika bahasa sebagai salah satu bentuk kebudayaan maka bahasa merupakan alat fikiran, alat akal yang ditemukan manusia untuk menjadi alat komunikasi dan saling mengerti dengan yang lainnya. ${ }^{4}$ Maka bahasa Arab sebagai bahasa resmi bangsa Arab dan merupakan bahasa yang mempunyai peranan penting bagi umat Islam sejak diutusnya Rasulullah SAW, sehingga bahasa Arab sangat identik dengan

${ }^{4}$ Ibid, h. 93 
agama Islam. Selain sebagai alat untuk mengungkapkan fikiran dan perasaan, bahasa ini juga berperan dalam perkembangan budaya Arab di seluruh negara. ${ }^{5}$

Bahasa Arab adalah bahasa kesatuan kaum muslimin sedunia, bahasa yang digunakan Allah SWT untuk berkomunikasi dengan hamba-Nya (Rasulullah SAW) yang disebut dengan al Qur'an yang akan tetap terjaga keasliannya sampai hari qiyamat, tak akan terkontaminasi oleh lajunya peradaban dunia. Selain itu bahasa Arab merupakan bahasa ilmu pengetahuan yang telah melahirkan karya besar dalam bidang filsafat, tasawuf, sejarah, ilmu kedokteran, budaya, satra, dan lain-lain. Tak heran jika PBB menjadikan bahasa Arab sebagai bahasa internasional setelah Spanyol.

Di dalam kitab Faid al-Qadir Syarh alJami' al-Sagir susunan Al-Manawiy, disebutkan bahwa dari Ibnu Abbas dengan riwayat Muslim, Rasulullah bersabda:
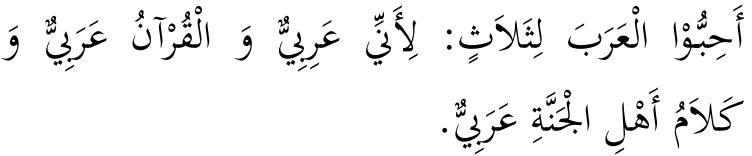

"Cintailah bahasa Arab karena 3 hal : Karena Aku (Nabi SAW) orang Arab, Al Qur'an menggunakan bahasa Arab, dan percakapan ahli surga adalah bahasa Arab.

\section{Umar bin Khattab ra berkata:}

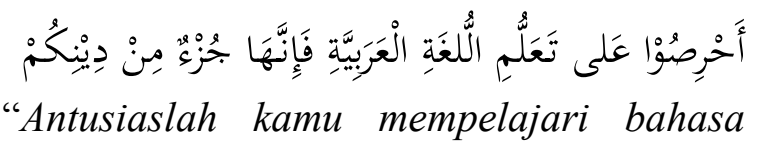

${ }^{5}$ Azhar Arsyad, Madkhal ila Thuruq Ta'lim al Lughah al 'Ajnabiyyah, (Mesir: Maktabah An Nahdhah Al Mishriyyah, 1999), h. 3
Arab karena bahasa Arab itu merupakan bagian dari agamamu”.

Dari sekian banyak keutamaan bahasa Arab, Indonesia patut bangga karena bahasa sebagai hasil budaya Arab ini juga mempunyai andil besar dalam kebudayaan Indonesia. Sampai saat ini kita masih merasakan dan melihat bukti pengaruh bahasa Arab terhadap kebudayaan Indonesia, ketika kita membaca buku, surat kabar, majalah dan lainnya, terkadang muncul bahasa Indonesia yang sangat mirip dengan bahasa Arab. Selain itu bahasa Arab tidak hanya merupakan bahasa agama Islam yang hidup di lingkungan ulama-ulama, santri-santri, pesantren-pesantren, madrasah-madrasah dan cendikiawan Islam, tetapi turut membina dan mengembangkan bahasa Indonesia dan bahasa-bahasa daerah yang tersebar di seluruh pelosok nusantara.

Selain bahasa, seni dan adat istiadat di Indonesia juga mengalami pencampuran dengan bahasa Arab. Terutama jika bagian daerah Indonesia tersebut sangat kental akan keIslamannya.

\section{Pengaruh bahasa Arab di dalam bahasa Indonesia}

Seperti yang telah dipaparkan di atas, kedudukan bahasa Arab di dalam masyarakat dan kebudayaan Indonesia yang dimulai sejak masuknya agama Agama Islam ke tanah air, telah mengambil bagian dalam kehidupan masyarakat Indonesia. 
Misalnya kata-kata yang berasal dari bahasa Arab yang telah masuk ke dalam bahasa Indonesia dalam bentuk yang bermacammacam, Di bawah ini akan diuraikan bentuk-bentuk kata yang berasal dari bahasa Arab.

a. Lafaz dan arti kata sesuai dengan aslinya, contohnya:

- Abad, abadi, adil, abdi, ahad, ahli, amin

- Bakhil, baligh, bathil, bai'at

- Khas, khitan, khatam, khusus

- Hadits, hadir, hadiah, hijrah, hukum, haid, halal, haram, hibah

- Rabbi, rahmad, rasul, riya, riba, risalah

- Sabar, saham, sahabat, salam, sahur, salju, syukur, dll.

b. Lafaz berubah dari aslinya tetapi memiliki arti yang sama, contohnya:

- Berkah dari kata barakah

- Derajar dari kata darajah

- Kabar dari kata khabar

- Selamat dari kata salamah

- Mungkin dari kata mumkin

- Sedekah dari kata Shadaqah, dll.

c. Lafaz dan arti kata berbeda dari aslinya, contohnya:

\begin{tabular}{|c|c|c|c|c|}
\hline \multirow{2}{*}{ No } & \multicolumn{2}{|c|}{ Bahasa Arab } & \multicolumn{2}{|c|}{ Bahasa Indonesia } \\
\hline & Kata & Arti & Kata & Arti \\
\hline 1 & Qashidah & $\begin{array}{l}\text { Kumpulan } \\
\text { dari beberpa } \\
\text { bait sya'ir } \\
\text { yang } \\
\text { berakhiran } \\
\text { huruf/bunyi } \\
\text { yang sama }\end{array}$ & Qosidah & $\begin{array}{l}\text { Lagu-lagu } \\
\text { Arab atau } \\
\text { irama } \\
\text { padang } \\
\text { pasir }\end{array}$ \\
\hline 2 & Qaul & Perkataan & Kaul & Bernazar \\
\hline 3 & I'tiqad & Keyakinan & I'tikad & Berniat \\
\hline 4 & Syahadatain & $\begin{array}{l}\text { Dua kalimat } \\
\text { syahadat }\end{array}$ & Sekaten & $\begin{array}{l}\text { Tradisi } \\
\text { perayaan } \\
\text { di Jawa } \\
\text { Tengah, } \\
\text { Para raja } \\
\text { dan wali } \\
\end{array}$ \\
\hline
\end{tabular}

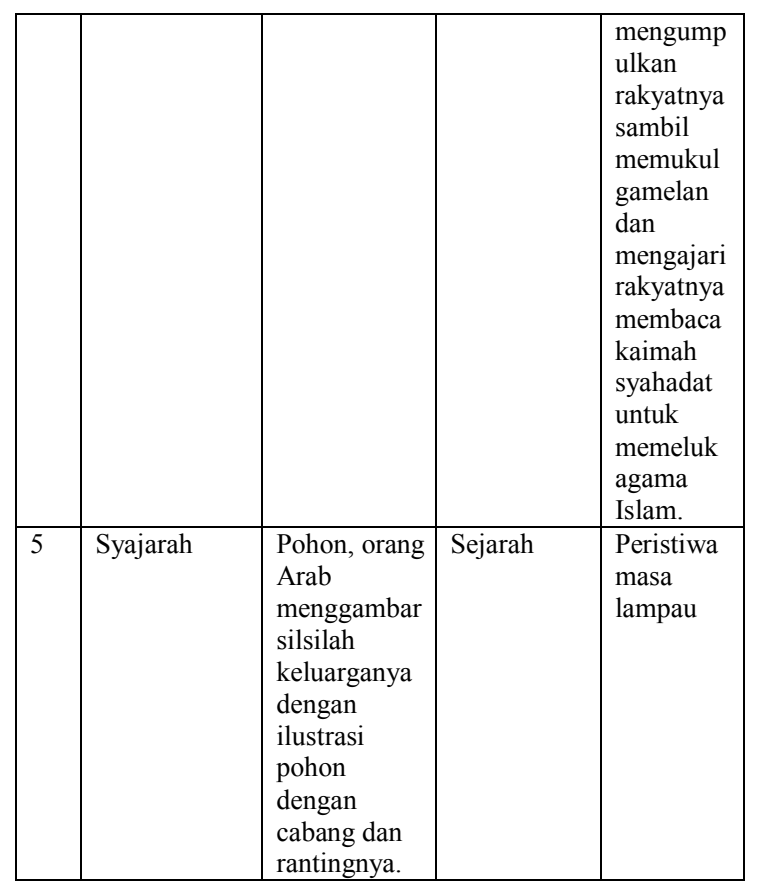

d. Lafaz sama namun memiliki arti yang berbeda, contohnya:

\begin{tabular}{|c|l|l|l|}
\hline No. & \multicolumn{1}{|c|}{ Kata } & $\begin{array}{c}\text { Arti dalam } \\
\text { B. Arab }\end{array}$ & \multicolumn{1}{|c|}{ Arti dalam B. Indonesia } \\
\hline 1 & Kalimat & Kata-kata & Kumpulan dari beberapa kata \\
\hline 1 & Kalimat & Kata-kata & Kumpulan dari beberapa kata \\
\hline 2 & Ustadz & Profesor & $\begin{array}{l}\text { Orang yang faham tentang } \\
\text { ajaran agama Islam }\end{array}$ \\
\hline 3 & Kuliah & Fakultas & $\begin{array}{l}\text { Belajar di lembaga perguruan } \\
\text { tinggi }\end{array}$ \\
\hline 4 & Daftar & Buku & $\begin{array}{l}\text { Catat, terdaftar = tercatat } \\
\text { Nama-nama yang diurutkan } \\
\text { dalam suatu tabel }\end{array}$ \\
\hline 5 & Sya'ir & Penyair & $\begin{array}{l}\text { Kumpulan dari beberpa bait } \\
\text { sya'ir yang berakhiran } \\
\text { huruf/bunyi yang sama }\end{array}$ \\
\hline
\end{tabular}

e. Nama-nama orang Indonesia yang berasal dari bahasa Arab

Nama yang dipakai oleh orang Indonesia juga banyak berasal dari bahasa Arab, terutama jika orang tersebut beragama Islam, contohnya: Abdullah, Abdul Lathif, Abdur Rahman, Ahmad, Muhammad, Mahmud, Hamid, Hamdani, Umar, ali, Saifullah, Saifuddin, Syamsuddin, Jamaluddin, Rahmi, Salim, Fakhri, Hidayat, Zainab, Fatimah, Siti Nurjannah, Husnul Khatimah, dll. 


\section{Huruf Arab sebagai tulisan Melayu}

Hingga sekarang, huruf Arab harus dipelajari khususnya bagi mereka yang mempelajari kesusasteraan Indonesia. Huruf Arab yang dipakai di Indonesia itu disebut dengan huruf Arab melayu/huruf Jawi. Walaupun ada sedikit perbedaan karena ada beberapa huruf di bahasa Indonesia tidak ditemukan dalam bahasa Arab, namun huruf hijaiyah yang dipakai oleh orang arab ini tetap menjadi acuan dalam penulisan huruf Melayu.

Pada era 90an dan awal tahun 2000 sekolah di Riau memiliki mata pelajaran Arab Melayu yang merupakan program wajib kurikulum dasar muatan lokal. Tentunya program ini memberikan kontribusi positif untuk melestarikan budaya. Aksara Arab Melayu sudah lama tumbuh dan berkembang dalam sejarah peradaban nusantara yang teraktualisasi pada ceritacerita rakyat, sya'ir, hikayat, gurindam, pantun, petuah, dan lain-lain. Perkembangan kesusasteraan melayu ditandai dengan penggunaan huruf Arab Melayu, masyarakat Melayu merasa tulisan tersebut telah menjadi milik dan identitas mereka.

Pada Awalnya, huruf arab Melayu atau Jawi menjadi media universal di Nusantara yang dapat dilihat dari surat rajaraja Nusantara ditulis dalam Aksara Arab Melayu/Jawi, sebagian besar karya sastra nusantara seperti Hikayat Hang Tuah, Hikayat Raja-Raja Pasai, dll ditulis dalam huruf Arab Melayu, begitu pula dengan cap atau stempel kerajaan dan mata uang di awal penjajahan yang diterbitkan oleh VOC juga menggunakan huruf tersebut.

Dengan adanya visi Riau 2020 yang menjadikan Riau sebagai pusat Kebudayaan Melayu di Asia tenggara, sebagian besar masyarakat kembali mengenal dan mengerti aksara arab Melayu melalui berbagai program pemerintah tentang cagar alam seperti papan nama jalan di Riau. ${ }^{6}$

Dengan tulisan arab Melayu ini telah ditulis dan dikarang ratusan buku tentang ibadah, hikayah, suluk, tasawuf, dan sejarah eperti yang pernah ditulis oleh Syeikh Syamsuddin As Sumatrani, Syeikh Arsyad Al Banjari, Syeikh Abdus Samad Al Jawi Falembangi, Syeikh Nawawi Al Jawi Al Bantani, dll.

Pada masa penjajahan belanda sebelum diajarkan tulisan latin di sekolahsekolah, orang Indonesia menggunakan tulisan Arab dalam surat menyurat. Bahkan banyak ditemukan orang Indonesia yang buta huruf tulisan latin namun mampu membaca dan menulis huruf Arab, sekurang-kurangnya mereka mampu membaca AlQur'an walapun pada saat itu orang yang tidak mampu membaca dan menulis huruf latin dianggap sebagai orang yang buta huruf. Di bawah ini ada beberapa

\footnotetext{
${ }^{6}$ Wisata Pekanbaru, "Aksara Arab Melayu, Khazanah Budaya Riau" dalam www.wisatapekanbaru.com, diunduh pada 19 Desember 2012
} 
contoh penggunaan huruf Arab Melayu pada papan nama:
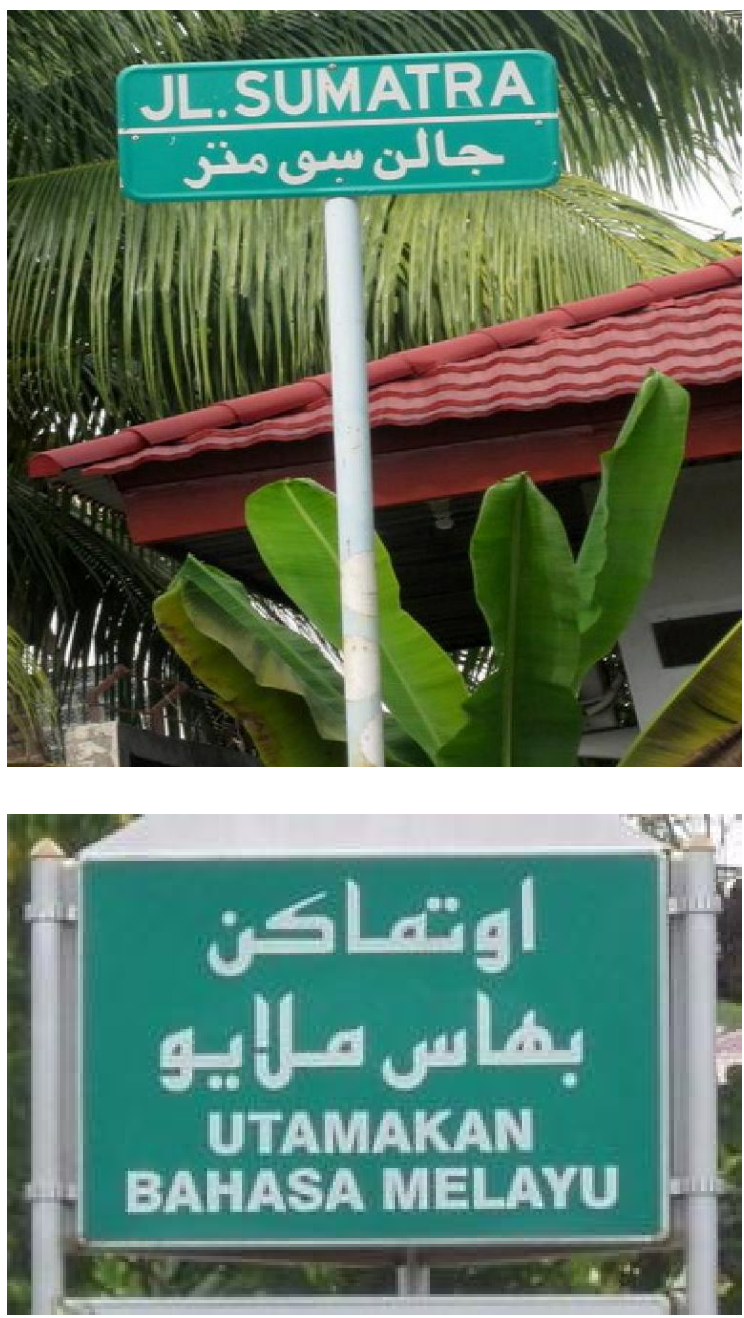

\section{Bahasa Arab dan kesenian}

a. Seni kaligrafi

Di Indonesia, kaligrafi merupakan bentuk seni budaya Islam yang pertama kali ditemukan, bahkan ia menandai masuknya Islam ke Indonesia. Hasil penelitian tentang data arkeologi kaligrafi Islam yang dilakukan oleh Prof. Dr. Hasan Muarif Ambary, kaligrafi gaya Kufi telah berkembang pada abad XI, dibuktikan dengan adanya batu nisan makam Fatimah Binti Maimun di Gresik (wafat 495 H/1082 M) dan beberapa makam lainnya pada abad ke-
$15^{7}$

Pada Abad ke XII-XX, kaligrafi beralih menjadi kegiatan kreasi seniman Indonesia yang diwujudkan dalam aneka media seperti kayu, kertas, logam, kaca, dan media lainnya. Buku pelajaran tentang kaligrafi pertama kali baru keluar sekitar tahun 1961 karangan Muhammad Abdur Razaq Muhili yang berjudul "Tulisan Indah" serta karangan Drs. Abdul Karim Husein yang berjudul "Khat, Seni Kaligrafi: Tuntunan Menulis

Halus Huruf Arab" tahun 1971. Kemudian dilanjutkan oleh para tokoh kaligrafi lainnya di Indonesia.

Perkembangan kaligrafi di Indonesia ditandai dengan kaligrafi dijadikan sebagai salah satu cabang yang diperlombakan dalam even MTQ. Pada awalnya dipicu oleh sayembara kaligrafi pada MTQ Nasional yang ke XII pada tahun 1981 di Banda Aceh, dan MTQ nasional yang ke XIII di Padang tahun 1983 yang dikirim dari berbagai daerah, namun karena dianggap kurang efektif maka hingga sekarang perlombaan kaligrafi dibuat di tempat MTQ berlangsung. Adapun jenis kaligrafi yang diperlombakan dalam MTQ adalah Khath Naskah, Khath Hiasan Mushaf, dan Khath Dekorasi. Di bawah ini akan disajikan beberapa contoh dari masing-masing jenis

\footnotetext{
${ }^{7}$ Hilyatul Qalam, "Sejarah Perkembangan Kaigrafi di Indonesia",dalam https://hilyatulqalam.wordpress.com
} 
kaligrafi yang diperlombakan pada even MTQ.

\section{Khath Naskah}

(Ditulis di atas kertas karton dengan qalam dan tinta)
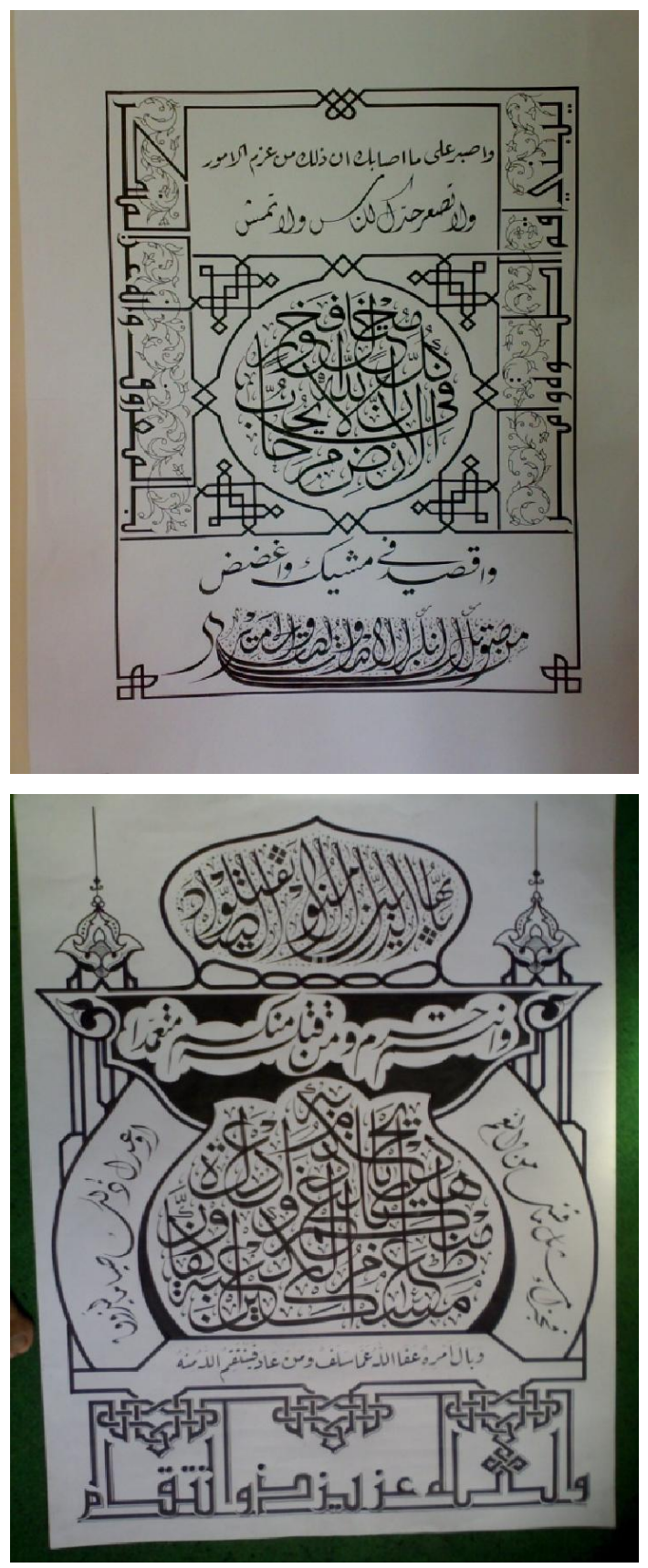

\section{Khath Hiasan Mushaf}

(Ditulis di atas kertas karton dan menggunakan cat)

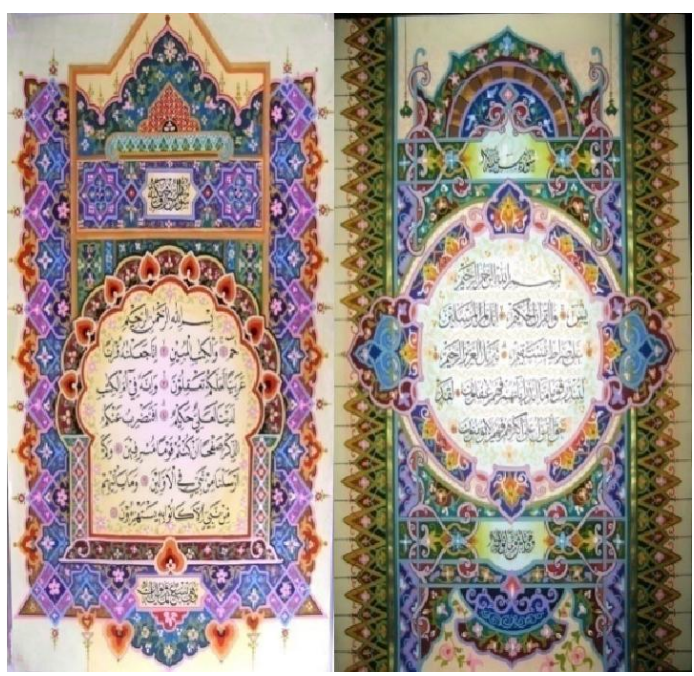

\section{Khath Dekorasi}

(Ditulis di atas triplek dan menggunakan cat)

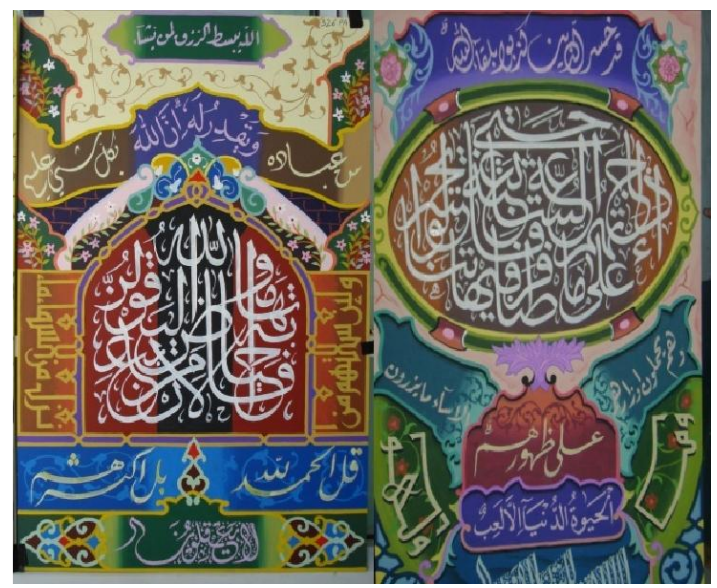

Seni kaigrafi ini tidak hanya dijadikan sebagai salah satu cabang MTQ di Indonesia. Dengan bentuknya yang indah dan mampu memberi ketenangan pada penikmatnya, kaigrafi ini sering digunakan sebagai hiasan dekoratif pada suatu bangunan terutama Masjid. Penulisan kaligrafi yang berisikan ayat-ayat Al-Qur'an pada dinding-dinding masjid akan menam- 
bah nilai estetika dan kenyamanan dari masjid tersebut.

\section{b. Seni suara}

Keberadaan bahasa Arab di Indonesia juga bergerak di bidang seni suara. Perkembangan seni suara akhir-akhir ini ditandai dengan minculnya para penyanyi singel atau grup yang membawakan irama lagu bernafaskan Islam seperti shalawat, nasyid, qasidah, dll yang menggunakan bahasa Arab pada lirik lagunya.

Nasyid adalah salah satu seni Islam dalam bidang seni suara yang bercorak Islam, mengandung nasihat, kisah para Nabi, memuji allah dan sejenisnya. Biasanya nasyid dinyanyikan secara acappela yang hanya diiringi gendang. Cara ini muncul karena banyak dari para ulama yang melarang penggunan alat musik yang berlebihan. Nasyid masuk ke Indonesia sekitar era 80 an. Perkembangannya diawali oleh aktivis-aktivis Islam yang menyanyikan syair-syair asli berbahasa Arab dan pada akhirnya berkembang dengan adanya nasyid berbahasa Indonesia yang dinyanyikan dalam acara pernikahan atau perayaan hari besar umat Islam. ${ }^{8}$

Adapun qasida pada dasarnya merupakan bentuk syair epik kesusasteraan Arab yang dinyanyikan berisi puji-pujian untuk kaum muslim. Dalam artian yang lebih luas,

\footnotetext{
8 Wikipedia, "Nasyid di Indonesia", dalam https://id.mwikipedia.org
}

qasidah adalah seni suara yang bernafaskan Islam, di mana lagu-lagunya banyak mengandung unsur akwah-dakwah Islamiyah dan nasihat-nasihat sesuai ajaran Islam. Biasanya lagu-lagu tersebut dinyanyikan dngan irama kegembiraan hampir menyerupai irama Timur Tengah yang diiringi dengan rebana, yaitu sejenis alat tradisional yang terbuat dari kayu berbentuk lingkaran yang pada salah satu sisinya ditutup dengan kulit hewan yang telah dibersihkan.

Pada awalnya rebana berfungsi sebagai intrumen dalam menyanyikan lagulagu keagamaan berupa puji-pujian kepada Allah SWT. Dan rasul-rasulNya. Oleh sebab itulah ia disebut dengan rebana yang berasal dari kata rabbana (suatu doa dan pujian kepada Allah SWT.). ${ }^{9}$

\section{Bahasa Arab dan adat istiadat Indonesia}

Bahasa Arab tidak hanya bahasa AlQur'an, bahasa Agama Islam, yang tumbuh di kalangan pesantren, madrasah, cendikiawan, ulama, santri, dan perguruan tinggi Islam. Lebih dari itu, bahasa Arab berperan penting dalam kebudayaan Indonesia. Misalnya pada upacara sekaten di Kraton Surakarta dan Yogyakarta, upacara adat, perkawinan, khataman, khitanan, mauludan pada bulan Rabiul Awal, Rajaban, Ruwahan (dari kata-kata arwah), Isra' Mi'raj, Upacara Asyura dengan bubur suraunya pada tanggal

\footnotetext{
${ }^{9}$ Wikipedia, "Kasidah", dalam https://id.mwikipedia.org
} 
10 Muharam, olah raga debus, sampai kepada kata-kata suci yang mengandung makna di dalam mantera-mantera yang masih dipercaya dan digunakan oleh sebagian masyarakat Indonesia, seperti aliran kebatinan yang menggunakan bahasa Arab dalam upacara mereka. ${ }^{10}$

Di Indonesia, masih kita temukan masyarakat awam menggunakan bahasa Arab baik itu dari ayat-ayat Al-Qur'an atau Hadits-Hadits Nabi Muhammad SAW, untuk kepentingan mistis/sakral seperti jimat, adanya kepercayaan bahwa nama yang digunakan dari bahasa Arab (Ahmad, Siti, Lukman, dll) akan membawa berkah, adanya pantangan membuang tulisan Arab karena akan ditimpa masalah. Adakalanya digunakan untuk perlindungan yang dikaitkan dengan kandungan ayat Al-Qur'an, misalnya Surat Yasin, Surat An- Nas, Surat Al-Falag dipercayai sebagai tolak bala, menghindari musibah atau menyembuhkan penyakit.

\section{Simpulan}

Kebudayaan Indonesia yang dipengaruhi oleh kebudayaan Arab adalah salah satu contoh akulturasi budaya. Ditandai dengan datangnya orang-orang Arab ke Indonesia pada abad ke-7 masehi, pada mulanya sebagai pedagang yang masuk

\footnotetext{
${ }^{10}$ Hariadi, "Peran Bahasa Arab dalam Agama dan Kebudayaan Nasional", dalam http://hariadipba.blogspot.com diunduh pada 19 Desember 2016
}

melalui India (Gujarat), dan kemudian berlanjut sebagai penyebar agama Islam. Ditambah lagi pengaruh agama Islam yang relatif cepat dapat diterima oleh bangsa Indonesia yang sejak awal sudah memiliki dasar-dasar religius. Sejak itulah bahasa sebagai salah satu unsur kebudayaan dengan sendirinya mengalami pencampuran dan pemindahan secara akulturasi, artinya bahasa Arab yang dibawa oleh orang Arab mengalami proses akulturasi dengan bahasa Indonesia. Walaupun Indonesia juga mengalami proses akulturasi dengan budaya Hindu-Budha, Belanda, Jepang, dan lainnya namun bahasa Arab juga telah memberikan sumbangan yang sangat besar dalam pertumbuhan bahasa Indonesia sebagai bahasa nasional. Wujud bahasa Arab dapat ditemukan pada:

1. Kata-kata bahasa Indonesia, seperti: Abad, abadi, adil, abdi, ahad, ahli, amin, Bakhil, baligh, batil, Abdullah, Abdul Lathif, Abdur Rahman, Ahmad, Muhammad, Mahmud, Hamid, Hamdani, Umar, ali, Saifullah, Saifuddin, dll.

2. Huruf Arab sebagai tulisan melayu

Di Indonesia, huruf Arab/hijaiyyah dijadikan sebagai acuan dalam penulisan huruf arab Melayu/Jawi. Dengan tulisan arab Melayu ini telah dikarang ratusan buku tentang ibadah, hikayah, suluk, tasawuf, dan sejarah eperti yang pernah ditulis oleh Syeikh Syamsuddin As Sumatrani, Syeikh 
Arsyad Al Banjari, Syeikh Abdus Samad Al Jawi Falembangi, Syeikh Nawawi Al Jawi

Al Bantani, dll.

3. Seni Indonesia

a. Kaigrafi

Kaligrafi merupakan bentuk seni budaya Islam yang pertama kali ditemukan, bahkan ia menandai masuknya Islam ke Indonesia. Selain memperindah bangunan masjid atau bangunan lainnya, kaligrafi juga menjadi salah satu cabang yang diperlombakan pada MTQ di Indonesia.

b. Seni suara

Keberadaan bahasa Arab di Indonesia juga bergerak di bidang seni suara. Perkembangan seni suara akhir-akhir ini ditandai dengan minculnya para penyanyi singel atau grup yang membawakan irama lagu bernafaskan Islam seperti shalawat, nasyid, qasidah, dll yang menggunakan bahasa Arab pada lirik lagunya.

\section{Adat Istiadat}

Bahasa Arab juga terlihat pada adat istiadat Indonesia, misalnya pada upacara sekaten di Kraton Surakarta dan Yogyakarta, upacara adat, perkawinan, khataman, khitanan, mauludan pada bulan Rabiul Awal, Rajaban, Ruwahan (dari katakata arwah), Isra' Mi'raj, Upacara Asyura

\section{Daftar Pustaka}

Ahmad Afwan Yazid, "Penggunaan Aspek Budaya dalam Pengajaran Bahasa Arab, dalam azzead-wordpresscom.cdn.ampproject.org, diundunh 4 tahun lalu

Akhmad Muzakki, Pengantar Teori Sastra Arab, Malang: UIN Maliki Press, 2011

Azhar Arsyad, Madkhal ila Thuruq Ta'lim al Lughah al 'Ajnabiyyah, Mesir: Maktabah An Nahdhah Al Mishriyyah, 1999

Bahrum Rangkuti dan Kafrawi, Pedoman Pengajaran Bahasa Arab, (Jakarta: Proyek Pengembangan Sistim Pendidikan Agama Departemen Agama RI, 1974

Budi W, "Seminar Internasional Peranan Bahasa Arab dalam Pengembangan Peradaban", dalam gudeg.net/read/5612/seminarinternasional

Ethantfz, "Pentingnya Bahasa Arab di Era Globalisasi", dalam elfaiznamjhawordpress-com.cdn.ampproject.org, diunduh 5 tahun yang lalu

Hariadi, "Peran Bahasa Arab dalam Agama dan Kebudayaan Nasional", dalam http://hariadipba.blogspot.com diunduh pada 19 Desember 2016

Hilyatul Qalam, "Sejarah Perkembangan Kaigrafi di Indonesia", dalam https://hilyatulqalam.wordpress.com

Koentjaraningrat, Kebudayaan Mentalitas Pembangunan, Jakarta: Gramedia, 1990

Mohammad Khoiron, "Bahasa Arab dan Islam Nusantara", dalam www.kompasiana.com, diunduh pada 06 Mei 2016 
Warteg Kampus, "Peranan Bahasa Arab Terhadap Bahasa Indonesia", dalam http://capslock07.blogspot.com, diunduh pada 04 Mei 2017

WisataPekanbaru, "Aksara Arab Melayu, Khazanah Budaya Riau" dalam www.wisatapekanbaru.com, diunduh pada 19 Desember 2012

Wikipedia, "Nasyid di Indonesia", dalam https://id.mwikipedia.org

Wikipedia, "Kasidah", dalam https://id.mwikipedia.org 
164 | II-Fathin Vol. 1 Edisi Juli-Desember 2018 